\title{
A cena em directo A madrugada e o despertar da fotografia de cena
} Filipe Figueiredo

$>1|2| 3$

Retrato do actor Eduardo Brasão como Monsenhor na peça A madrugado. Postais ilustrados a partir de fotografia de A. Bobone. Biblioteca

Arquivo do Teatro Nacional de D. Maria II.

Filipe Figueiredo

é Doutorando em Estudos de Teatro na Faculdade de Letras da Universidade de Lisboa

e lnvestigador no Centro de Estudos de Teatro da Faculdade de Letras da Universidade de Lisboa (CET/FLUL).
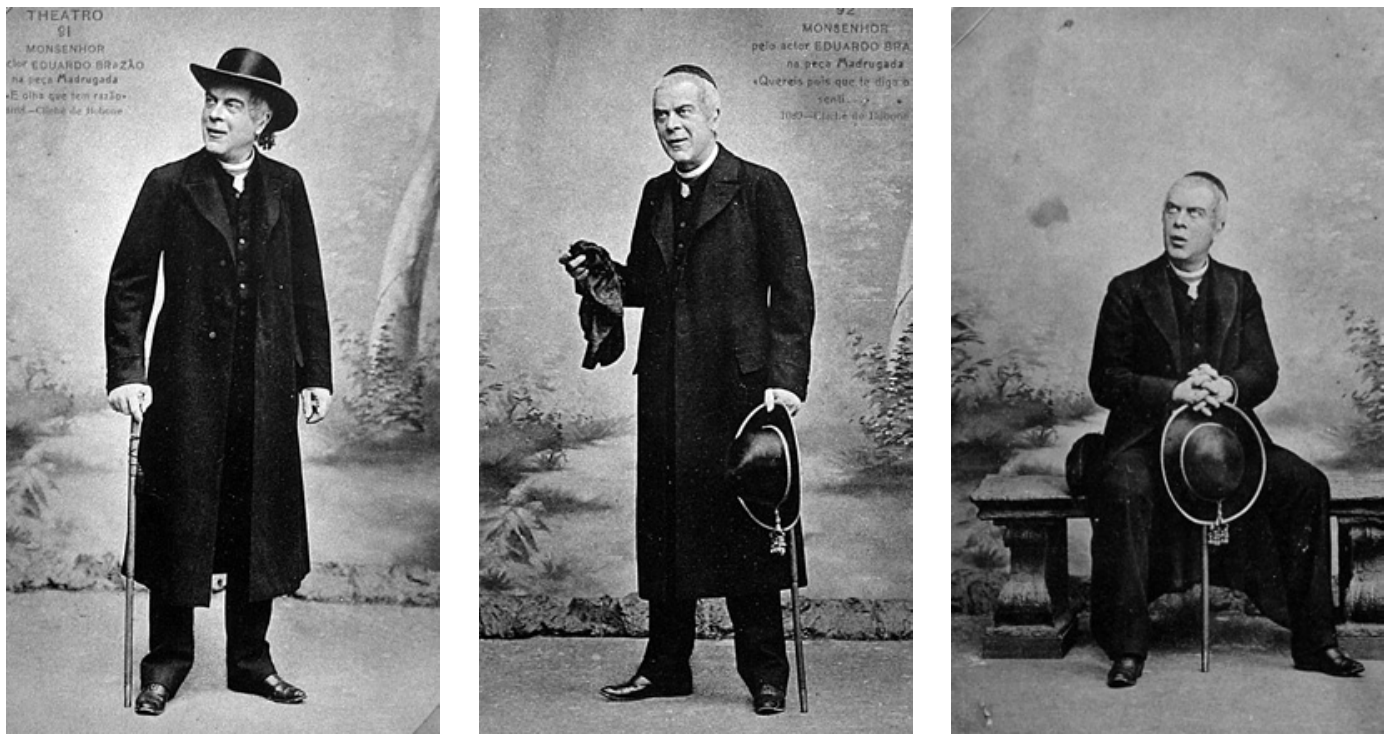

O álbum de Eduardo Brasão e as fotografias de A madrugada

Preservado no Museu Nacional do Teatro (MNT), um conjunto de álbuns de recortes de imprensa e breves legendas manuscritas permite mergulhar em parte significativa da vida artística do actor e empresário Eduardo Brasão e de uma das companhias mais famosas do último quartel do século XIX - a Rosas \&t Brasão. Estes álbuns, provavelmente criados pelo actor e integrados no seu espólio, agora à guarda do MNT, percorrem um periodo vasto que, apesar de alguns hiatos, vai de 1874 a 1925, fechando com a notícia da morte do actor Eduardo Brasão. Temperados pelo tempo e pelas vicissitudes de uma qualquer inundação em caves barrentas, provavelmente na propriedade de Brasão, na freguesia do Gradil (Mafra) de onde foram resgatados, as suas páginas têm a rigidez de pergaminhos e os recortes de imprensa, noticiando a actividade de Brasão e das suas companhias, provavelmente colectados pelo próprio, permanecem selados por uma fina camada de barro de tons ocres. Abre-se o álbum correspondente ao período de 1892 a 1893 e, ao cabo de algumas páginas, uma folha à esquerda revela a $1^{\text {a }}$ página de 0 António Maria de 30 de Abril que anunciava, com as costumeiras caricaturas de Rafael Bordalo Pinheiro, a peça de Fernando Caldeira A madrugada, representada pela primeira vez em 26 de Abril de 1892, no Teatro Nacional
D. Maria II. Na página da direita, uma legenda manuscrita - "Abril de 1892" - articula-se com a decoração desenhada de motivos florais que preenche os espaços entre recortes de jornal (três colunas do jornal 0 tempo do dia seguinte à estreia da peça). No topo da página, destaca-se uma fotografia colada representando uma das cenas da peça e, nas páginas seguintes, mantém-se o mesmo esquema distribuindo um total de doze fotografias, que remetem para o espectáculo, ao longo de nove páginas de recortes, sem qualquer relação das imagens com o conteúdo dos recortes. As imagens escapam a qualquer lógica ilustrativa do texto, que apenas encontraria na primeira notícia um estilo mais narrativo em relação ao espectáculo. Os restantes recortes referem-se quase sempre à estreia, à qualidade do desempenho dos actores ou ao mérito do texto e do seu autor, e não permitem estabelecer qualquer associação com as imagens. Surgem, pois, de imediato algumas questões que importa esclarecer a respeito destas fotografias: quando e onde foram produzidas? São fotografias de cena ou fotografias realizadas no estúdio do fotógrafo? Qual a relação que é possivel estabelecer entre estas imagens e o espectáculo representado ou o texto teatral? Quem as fotografou e quais os seus responsáveis? Que proximidade existe entre estas imagens e as fotografias publicadas em postal ilustrado a parti do mesmo espectáculo? 


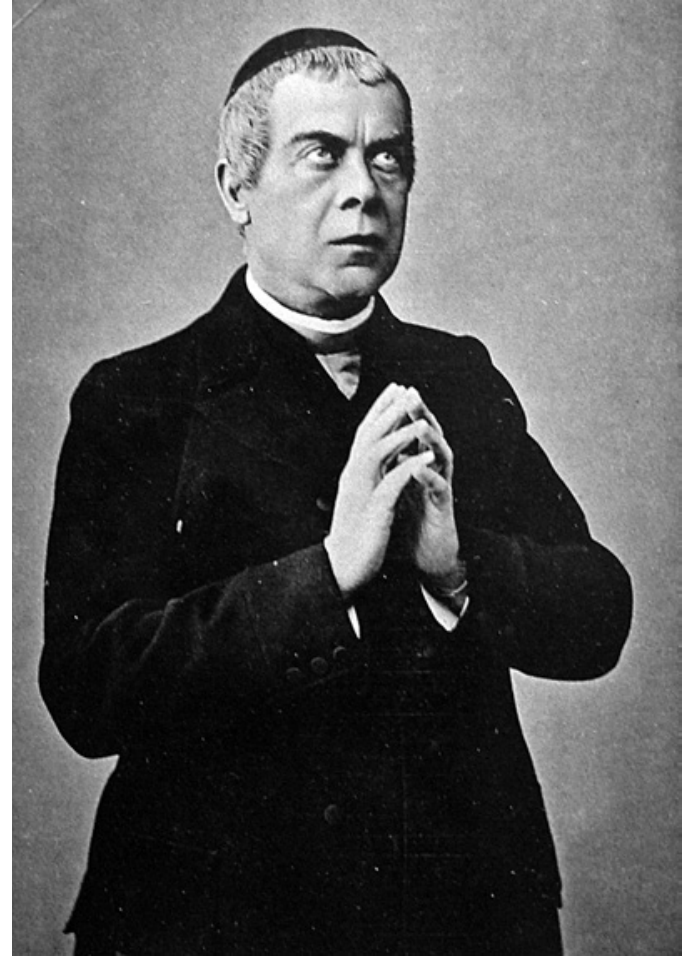

Datação das imagens

Deduzir a data das fotografias a partir da sua inscrição entre os documentos datados de Abril de 1892 seria muito frágil perante a incerteza de ter sido o próprio Brasão a montar o álbum e desconhecendo se o mesmo foi construido no tempo dos eventos e das notícias ou a posteriori, permitindo assim integrar outros documentos mais tardios. No entanto, a publicação do texto $A$ madrugada - Comédia em quatro actos ilustrada, em 1894, na Colecção Literária Portuguesa, fornece uma chave crucial para este processo de datação. Tal como acontece nas 2a e $3^{a}$ edições, respectivamente, em 1909 e 1913, a primeira edição, dita "ilustrada", reproduzia precisamente as mesmas imagens, além de uma reprodução na capa que replicava uma das fotografias do interior. Assim, no que toca à datação, pode dizer-se que as fotografias são seguramente anteriores a 1894, podendo a sua produção ser balizada entre esta data e o momento de apresentação do espectáculo, 1892.

Fotografia de cena ou fotografia de estúdio? A prática conhecida e documentada da fotografia de teatro tem mostrado que, no período em causa, a produção se caracteriza eminentemente por retratos de actor fotografados nos estúdios dos fotógrafos, de carácter "civil" e com o intuito de promover a identidade do retratado, a par de algumas outras fotografias - retratos de actor em personagem - que, não sendo fotografias de cena, propriamente ditas, estabelecem, contudo, uma proximidade com a mesma por via da pose, do guardaroupa e de alguns adereços. Estas fotografias são realizadas, como os retratos "à civil", no estúdio fotográfico, mas recorrem a adereços que são disponibilizados pelo fotógrafo ou que, nalguns casos, são transportados dos teatros para os estúdios de modo a permitirem construir um enquadramento minimamente relacional com a cena, fidedigno e referencial. Esta prática, abordada já por vários

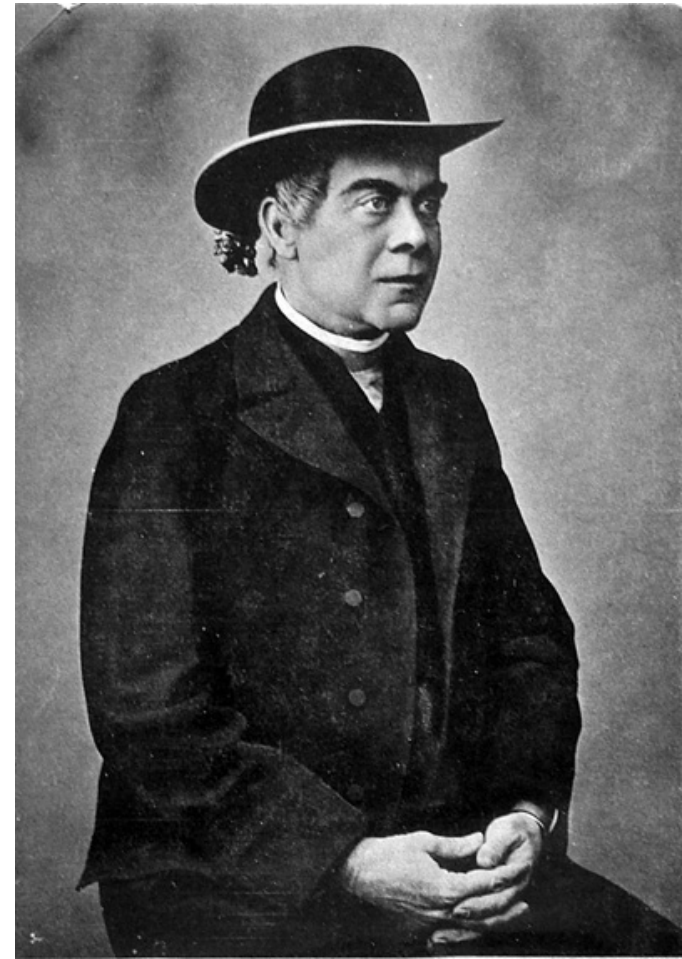

$<4 \mid 5$

Retrato do actor Eduardo Brasão como Monsenhor na peça A madrugada. Postal ilustrado a partir de fotografia de Arnaldo Fonseca. Biblioteca Arquivo do Teatro Nacional D. Maria autores (Balk 2002; Senelick 2002) decorre de diversos factores, particularmente das condições tecnológicas da fotografia por não se adaptar ainda convenientemente à diminuta luminosidade dos espaços teatrais, e tem permitido aceitar que não existe ainda, neste periodo, fotografia de cena captada directamente nas salas de teatro. Como consequência, essas fotografias resultam numa estandardização marcada pelo recurso a telões de fundo do estúdio do fotógrafo, que fazem as vezes do cenário, por vezes utilizados em mais do que uma reconstituição cenográfica - leia-se, retratos de actor em personagens com referência a mais do que uma peça como se pode verificar, por exemplo, na confrontação de postais publicados a partir de imagens das peças Afonso VI e D. César de Bazan ou O segredo de confissão e Tio Milhões. Outra caracteristica é ainda a construção da imagem privilegiadamente em torno de um só actor, com remissão para uma determinada cena em particular por si protagonizada.

Documentada desde o final da década de 1860, esta prática do retrato de actor em personagem acaba por ser consolidada nos últimos anos do século numa associação - que parece evidente - aos avanços tecnológicos na área da impressão gráfica, que permitem quer a sua difusão sob a forma de postais ilustrados, quer a sua publicação na imprensa, como acontece no Ocidente, Portugal-Brasil, Ilustração portuguesa, etc. Neste periodo finissecular, a Companhia Rosas \&t Brasão teve um papel preponderante na utilização destes recursos, tanto pelo seu carácter pioneiro, como pela extensa e sistematizada produção de retratos de actor em personagem, tornando-a num autêntico caso de estudo. A vasta produção de imagens associadas às encenações da Companhia Rosas \&t Brasão contribuiu para a produção de uma memória visual dos seus espectáculos de maior sucesso. E, por se tratar de uma das companhias de maior prestígio do teatro português, com residência concessionada no Teatro 


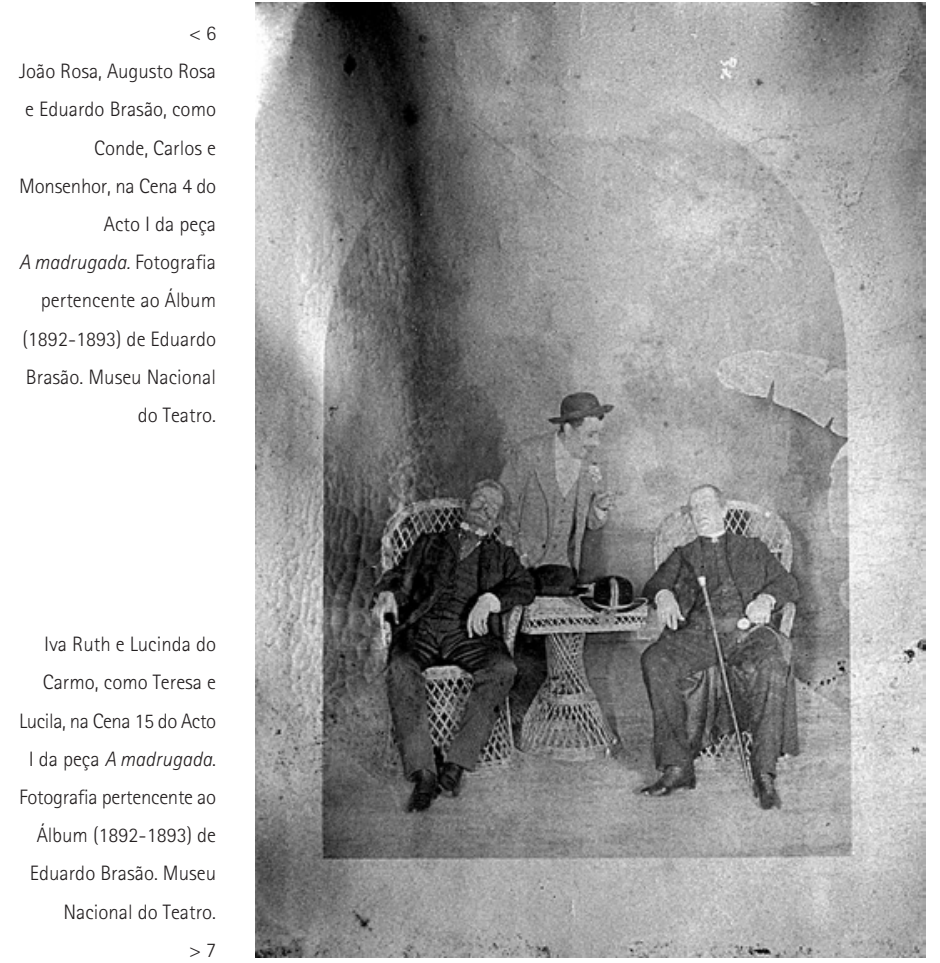

Nacional, esta prática contribuiu consequentemente para alimentar o imaginário da representação teatral deste período.

A vulgarização destes retratos, potenciada pela publicação em colecções temáticas de bilhetes postais exercício de produção visual próprio de uma nova época -, foi crucial para dinamizar uma prática de troca de retratos, oferecidos pelos actores entre si e aos fãs, tal como já acontecia com os formatos carte de visite ou outros. Em consequência, esses retratos, em especial os dos actores mais emblemáticos da companhia, como Eduardo Brasão, João Rosa e Augusto Rosa ou Rosa Damasceno, permitiram construir um percurso visual da carreira artística dos representados. 0 repertório do actor passa assim a ser reconhecido num conjunto de retratos que ganha grande dimensão simbólica das qualidades e capacidades do artista. Nas suas digressões, os actores fazem-se acompanhar deste sortido de imagens, como uma "carteira de apresentação", muitas vezes publicada na imprensa como forma de exibir o actor e os seus méritos. Tal aconteceu com Eduardo Brasão nas suas muitas viagens de tournée pelo Brasil, em cuja imprensa local as poses mais significativas do actor nos principais papéis do seu repertório escusavam grandes dilações na forma escrita e galvanizavam a identidade do actor. $\mathrm{Na}$ imprensa portuguesa, foram muitas vezes utilizadas nas inúmeras homenagens que as principais publicações prestavam aos artistas mais destacados. Na rúbrica "Os nossos actores", a llustração portuguesa apresentava ao público a imagem dos actores mais afamados e a ela também recorreu sempre que, por morte de tais figuras públicas, pretendeu homenageá-las e evocar, junto dos leitores, a memória das suas carreiras de palco. 0 mesmo acontecia nos programas das festas artísticas que lhes eram dedicadas. A intensa e diversificada utilização destas imagens conferiu-Ihes um estatuto próximo de "cromos" em que a imagem, replicada vezes sem conta, cristalizou

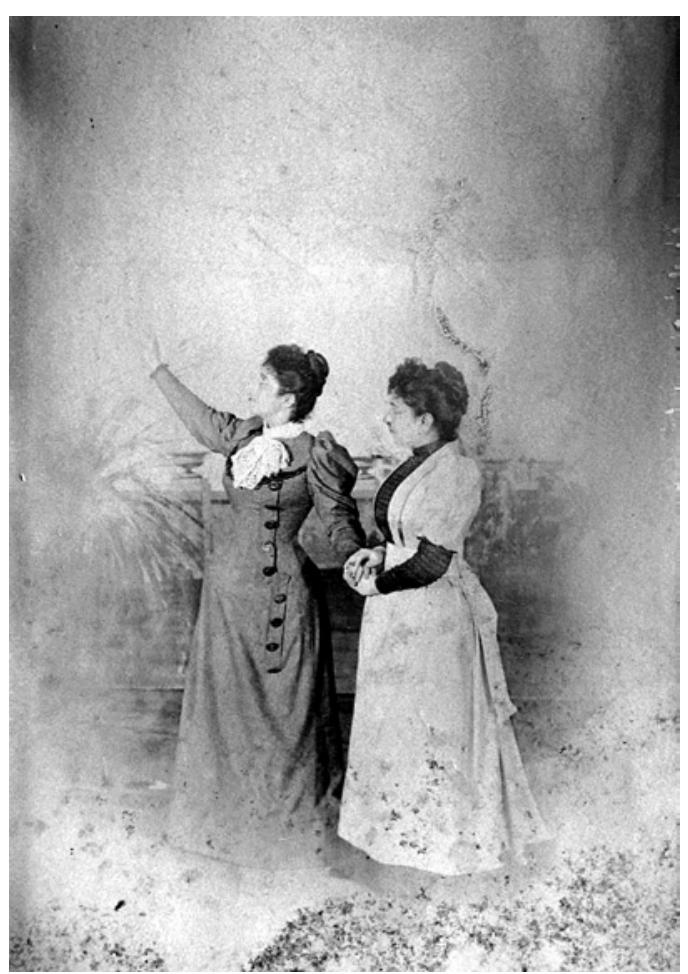

a identidade dos seus retratados. Ficaram, por isso, famosas algumas fotografias que remetem para representações de peças como Leonor Teles, Kean, 0 amigo Fritz, 0 bibliotecário, D. César de Bazan, D. Afonso VI, 0 abade Constantino, A madrugada, 0 Alfageme de Santarém, 0 segredo de confissão, Afonso de Albuquerque, ou Hamlet. entre outras.

Nos casos identificados de retratos de actor em personagem é comum eleger-se um ou dois momentos mais representativos da peça a partir do qual se realizam as produções fotográficas, por norma, centradas apenas numa personagem, sendo esta desempenhada por um dos actores de maior prestígio, reflectindo ainda uma "[...] concepção do teatro romântico, onde apenas importava que a grande estrela brilhasse num papel que lhe fornecesse todas as possibilidades de deslumbrar o seu público, descurando-se os restantes intérpretes e o espectáculo em geral [...]" (Santos 1979: 8). Resultam, assim, dessas situações imagens com poucas variações, ensaiando apenas algumas mudanças de pose e recorrendo a pequenas alterações do cenário e/ou adereços, e que são impressas como postais ilustrados.

\section{A madrugada em postal ilustrado}

No caso da peça A madrugada, as imagens publicadas em postal ilustrado e hoje conhecidas, num total de 5 (Fotos 1 a 5), representam todas a personagem do Monsenhor interpretada por Eduardo Brasão. Integram uma mesma colecção de postais - "Theatro" - (números 91 a 95), mas corresponderão a dois momentos diferentes de criação, considerando a diferença de autoria entre elas, apesar de não muito longe um do outro, a julgar tanto pela sequência numérica dos postais, como pela ausência de sinais de envelhecimentos no rosto do actor. Enquanto os três primeiros postais resultam de fotografias de Augusto Bobone, os dois últimos identificam Arnaldo Fonseca como $\mathrm{o}$ autor das imagens. Independentemente dessa 

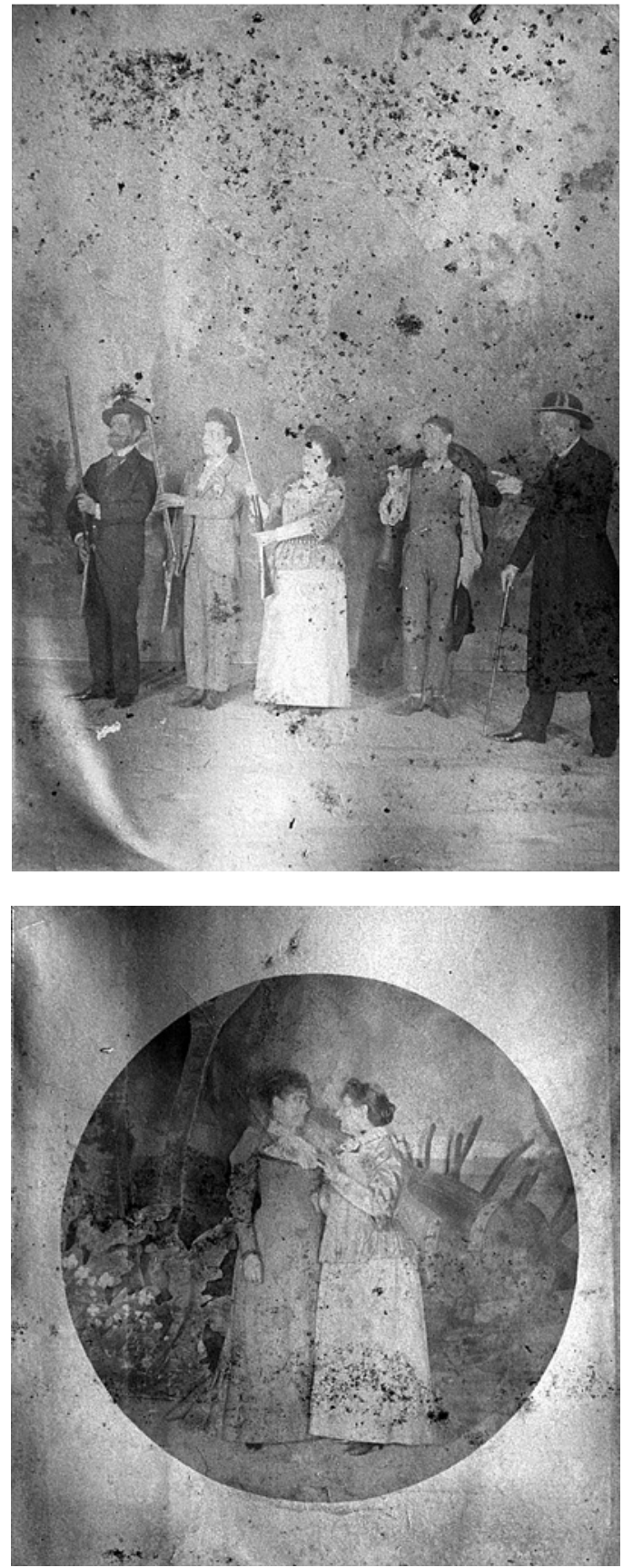

identificação, estes dois conjuntos revelam caracteristicas bem diferentes na construção do retrato: as imagens de Bobone são mais abertas incluindo o retrato de corpo inteiro em que o fundo e adereços contribuem para a construção da mise-en-scène aqui fotografada. Já nas imagens de Arnaldo Fonseca, verifica-se um ângulo bastante mais fechado que incide apenas sobre parte do corpo do actor e a sua expressão sobre um fundo neutro. Estas são, de resto, características presentes em grande parte da obra dos dois autores.

Um aspecto bastante curioso é o facto de todos estes retratos terem uma legenda que supostamente conduziria o observador a um momento da acção dramática. Contudo, esta inscrição revela-se como uma senha muito encriptada e pouco reveladora. Se num dos postais de Arnaldo Fonseca se pode ler a legenda despretensiosa "Uma das expressões" (postal no 95), já as outras - "E olha que tem razão" (postal no 91) (Foto 1), "Quereis pois que te diga o que senti" (postal no 92) (Foto 2), "Padre nosso que estais no céu" (postal no 93) (Foto 3) ou "Oh meu deus" (postal no 94) (Foto 4) - sugerem uma proximidade com uma cena em particular. No entanto, não é fácil reconhecer em todos os postais uma proximidade entre as imagens, as legendas e o texto. A legenda do postal 91 não se encontra no texto e a própria expressão do actor é pouco reveladora do sentido pretendido. A legenda "Quereis pois que te diga o que senti", do postal 92, tem no texto como equivalente mais próximo "Quereis pois que te defina o que sentes", na cena XVI do Acto II (página 136') e a expressão "Oh meu deus" da legenda do postal 94 nunca surge na fala de Monsenhor, mas em diversos momentos do texto de outras personagens. Só o postal 93 constitui uma excepção: a legenda corresponde exactamente à fala do Monsenhor na cena XII do Acto III (página 171) e a fotografia é muito semelhante à imagem existente no álbum de Brasão e utilizada na edição impressa do texto, precisamente antes do excerto do texto referido. Contudo, correspondem a momentos de captação distintos, já que os adereços são diferentes, nomeadamente o banco em que Monsenhor se encontra sentado.

Outro aspecto ainda possivel de analisar nos postais a partir das fotografias de Bobone é o carácter dos fundos. As três imagens dos postais referidos resultam de tomadas de vistas exactamente com o mesmo enquadramento, utilizando um fundo em que se representa o tronco de uma árvore do lado direito e alguma vegetação rasteira do lado esquerdo. No postal 93, porém, é acrescentado um adereço de cena, um banco de pedra, que denuncia o carácter adaptativo de que se revestiam as sessões fotográficas no estúdio do fotógrafo.

\section{A madrugada nas imagens do álbum de Brasão} Ao contrário do que acontece nestes postais ilustrados em que pequenos excertos do texto dramático procuram situar o "gestus" presente na imagem no decorrer da peça, as imagens coladas no álbum, por serem fotografias originais, não legendadas, surgem desamparadas em relação à sua leitura e à relação com o seu objecto referencial. Contudo, a consulta das edições do texto de Fernando Caldeira já antes referidas (1894, 1909 e 1913) dá um contributo crucial para esta contextualização, uma vez que a sua publicação acontece sempre no mesmo lugar no texto, com pequenas variações na sua disposição apenas com o intuito de harmonizar o layout das páginas em que se inserem. Pode depreender-se, perante a constância da paginação, que as imagens estabelecem, assim, uma relação directa com a cena junto da qual se situa. Analisado o seu posicionamento, verifica-se a regularidade da sua distribuição ao longo do texto - três imagens por cada acto - reflectindo um critério de selecção bastante claro: compor fotograficamente ilustrações que se refiram a momentos importantes, ainda que resgatando os de maior dramaticidade. Deste modo, cada uma das
$<8$

João Rosa,

Ferreira da Silva,

Rosa Damasceno, Alves e

Eduardo Brasão, como Conde, Ângelo, Berta,

Fagulha e Monsenhor,

na Cena 22 do Acto I da peça A madrugado. Fotografia pertencente ao Álbum (1892-1893) de Eduardo Brasão. Museu Nacional do Teatro. $<9$ Iva Ruth e Rosa Damasceno como Teresa e Berta, na Cena 10 do Acto Il da peça A madrugada. Fotografia pertencente ao Álbum (1892-1893) de Eduardo Brasão. Museu Naciona do Teatro.

Todas as indicações de página do texto de A madrugada têm como referência a $1^{\text {1a }}$ edição de 1894. 

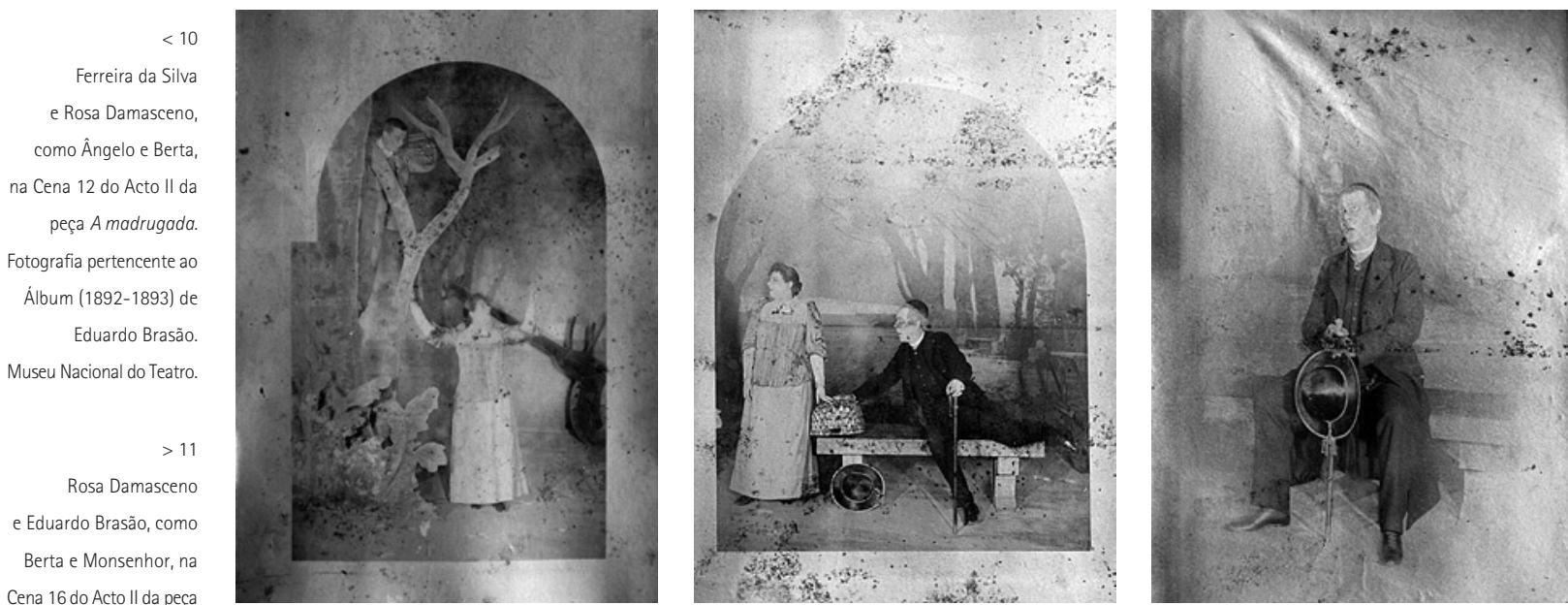

imagens refere-se a uma cena em particular, correspondendo, significativamente, quer à fala de uma das personagens, quer a um movimento de grupo de personagens ou uma qualquer situação prevista no texto.

Conquanto seja muito difícil delimitar os limites da categoria "fotografia de cena", assim como definir em absoluto o carácter referencial da fotografia, torna-se determinante para a sua análise verificar até que ponto existe na imagem uma contiguidade física, espacial, materia e emocional com o evento performativo ou se, pelo contrário, a imagem resulta de um simulacro cénico e representacional da cena, num contexto estranho ao do evento, por norma o estúdio fotográfico.

Se por um lado, as fotografias existentes no álbum de Eduardo Brasão apresentam algumas caracteristicas semelhantes aos retratos publicados em postais ilustrados analisados anteriormente, por outro, parecem escapar à uniformização do retrato de estúdio. Contrariamente aos retratos de actor em personagem, as fotografias do álbum integram grupos de duas ou mais personagens, com excepção feita para uma das imagens, em que Brasão representa a personagem do Monsenhor, numa composição com apenas uma personagem. Mas também no que respeita aos cenários, as diferenças são evidentes. Em vez de fundos preenchidos com telões únicos que servem normalmente para compor o cenário de várias imagens referentes à mesma peça e, não raras vezes, mesmo a peças diferentes, como já atrás se referiu, as fotografias de A madrugada, do álbum de Brasão, apresentam - cada uma - diferentes cenários com correspondência aos ambientes próprios de cenas distintas. Além disso, se de facto podem ser identificados fundos com telões de efeito trompe-l'oeil, também podem ser encontrados elementos com caracteristicas próprias de cenários tridimensionais, como vegetação rasteira e estruturas de simulação de árvores, que resultam em evidentes efeitos de profundidade. Deve ainda salientar-se que vários dos telões que podem ser vistos em algumas das imagens não são fundos de uso habitual nos estúdios fotográficos porque, por um lado, evidenciam uma escala de grandes dimensões e profundidade, e, por outro, contêm elementos muito particulares que se distanciam do carácter mais anódino dos usados pelos fotógrafos, que se querem aptos para situações de contextos muito variáveis.

Neste aspecto, algumas imagens são particularmente relevantes. Na fotografia da cena 12 do Acto II (Foto 10) no momento em que Berta e Ângelo procuram devolver a cria de passarinho ao ninho, para junto da progenitora, o cenário é composto por um telão de fundo com a representação de uma árvore, de encontro ao qual se encontra uma carroça de dimensões reais e alguns outros elementos. Entre estes elementos, a simulação dos troncos de uma árvore no qual Ângelo se empoleira com a gaiola uma outra estrutura que parece ser uma bambolina do palco de teatro e ainda vegetação rasteira - sendo difícil perceber se é verdadeira ou simulada - compõem um espaço de plena tridimensionalidade.

Outras imagens, cuja avaliação neste contexto se impõe, são as que respeitam ao Acto IV (Fotos 15 a 17) à entrada do qual se anuncia um novo cenário - a fachada de um palácio - e uma nova situação - uma sessão de assinatura das escrituras dos casamentos e um baile. Nas três fotografias que lhe correspondem, os actores adoptam um guarda-roupa mais adequado à situação cerimoniosa: Carlos, Conde e Ângelo vestem agora casaca, e Monsenhor enverga a batina comprida de tonalidade mais clara do que o fato e casaco negro que usa nas imagens anteriores. Teresa parece ter também mudado de vestido e as raparigas que aparecem na cena 17 do $4^{\circ}$ acto vestem trajos regionais completos - saias, coletes, lenço à cintura, brincos, chapéus - como é habitual em dias festivos. As três fotografias em causa denunciam o cenário de que se fala na introdução didascálica ao Acto IV, evidenciando estruturas, ou melhor o seu simulacro, com grandes dimensões. Os planos destas fotografias são relativamente fechados não permitindo obter uma impressão geral do palco, contudo a articulação das três imagens, como se ilustra (Foto 18), põe a descoberto uma extensão considerável do cenário do Acto IV: apesar das sobreposições que se verificam, a sequência de fotografias permite reconfigurar o telão de fundo que simula em trompe-l'oeil a "fachada do palácio com portas e grandes janelas à antiga" (Caldeira 1894: 215). 0 telão representa com grande realismo e pormenor o alçado de um edifício de aparato nobre e de inspiração neoclássica: uma casa de dois pisos separados por um friso contínuo em que se distinguem verticalmente dois corpos; no corpo da esquerda, uma porta ao centro, com moldura de cantaria em que se salientam dois finos colunelos adossados, encimada por um frontão semicircular, é ladeada por duas janelas com dois frontões semicirculares; no piso superior identificam-se três vãos, sendo o central ladeado também por dois colunelos adossados; o corpo da direita do edifício 

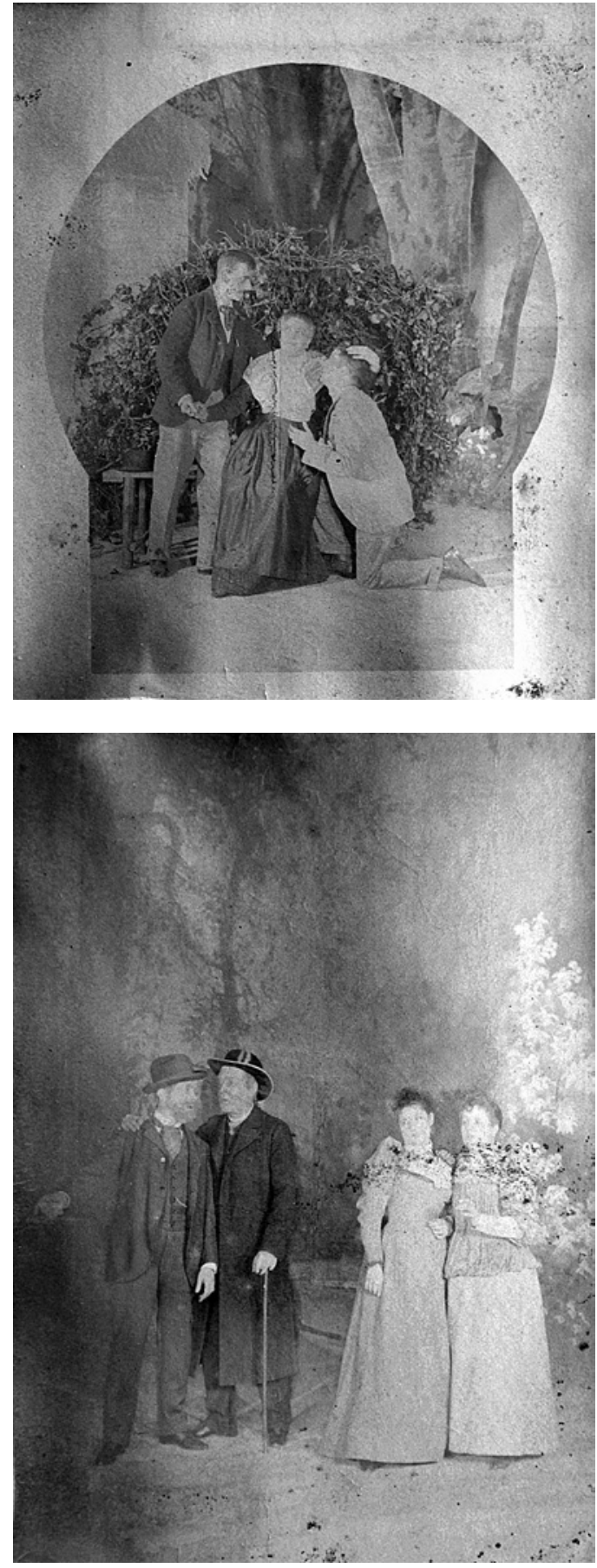

representado no telão, um pouco mais avançado do que a da esquerda, apresenta uma arcada, que sustenta o piso superior, composta por dois arcos assentes em colunas com capitéis decorados com volutas. Partindo das dimensões das figuras presentes nestas imagens, pode calcular-se que o cenário terá pelo menos uma extensão de cerca de oito metros por três metros e meio de altura, dimensões que devem exceder as utilizadas nos cenários de estúdios de fotógrafos. Além de extremamente particular nos motivos, o volume arquitectónico representado no telão sugere, na sua extensão, a adequação a diferentes momentos da peça, tal como se vê nas três imagens que se referem a este acto.

Outro aspecto de relevo presente nas fotografias do álbum diz respeito à iluminação. Enquanto as imagens
$<13$

Maia, Carolina Falco e Ferreira da Silva, como Jorge, Marieta e Ângelo, na Cena 18 do Acto III da peça A madrugada. Fotografia pertencente ao Álbum (1892-1893) de Eduardo Brasão. Museu Nacional do Teatro.

dos postais ilustrados apresentam uma luz suave e sem produzir sombras muito contrastadas, as fotografias do álbum são produzidas com uma luz dura e mais contrastante, provavelmente com recurso a fontes de iluminação eléctrica. Se nos estúdios fotográficos, normalmente com grandes vãos fenestrados por onde entrava a luz em grande quantidade, os fotógrafos estavam habituados a trabalhar com a luz natural, no palco do teatro as dificuldades sentidas eram maiores, ao ponto de terem impedido a sua representação fotográfica até àquele momento. As marcas de sombras muito contrastadas e, em alguns casos, com direcções sobrepostas, nas fotografias do álbum, denunciam a possibilidade de se tratar de iluminação artificial eléctrica na sala de teatro. Na verdade, não haveria necessidade para esse tipo de iluminação no estúdio. São visiveis as sombras pronunciadas na maior parte das imagens, o que não se vê nas imagens em postal, que resultarão de situações de estúdio com iluminação natural. Repare-se em algumas das seguintes fotografias, a título de exemplo: na fotografia da cena 22, do Acto I (Foto 8), as sombras das personagens da esquerda, Conde e Ângelo, desenhamse no sentido da esquerda para a direita, enquanto que a sombra de Monsenhor, no extremo direito da composição, se projecta precisamente no sentido oposto, da direita para a esquerda; na fotografia correspondente à cena 11 do Acto III (Foto 12), as sombras das pernas do Monsenhor, única personagem na imagem, cruzam-se uma sobre a outra denunciando duas fontes de luz distintas, enquanto as rugas do telão ao fundo reflectem os efeitos de uma iluminação dura; noutro caso, na fotografia da cena 12 do Acto II (Foto 10), a luz extremamente dura e rasante produz uma replicação da forma da carroça que se encontra no fundo.

\section{Notas finais}

Considerando a diversidade cenográfica aqui presente e as suas características, bem como a composição com grupos de personagens e a natureza da iluminação, as fotografias de A madrugada do álbum de Brasão, realizadas entre 1892 e 1894, permitem falar de imagens produzidas dentro do teatro, directamente sobre a cena que decorre no palco, ainda que em resultado de uma sessão preparada para este fim em particular. Embora não seja possivel identificar por agora nem o fotógrafo responsável por estas fotografias nem, tão pouco, quem as encomendou
João Rosa,

Eduardo Brasão, Iva Ruth e Rosa Damasceno, como Conde, Monsenhor, Teresa e Berta, na Cena 18 do Acto III da peça A madrugada. Fotografia pertencente ao Álbum (1892-1893) de Eduardo Brasão. Museu Nacional do Teatro. 

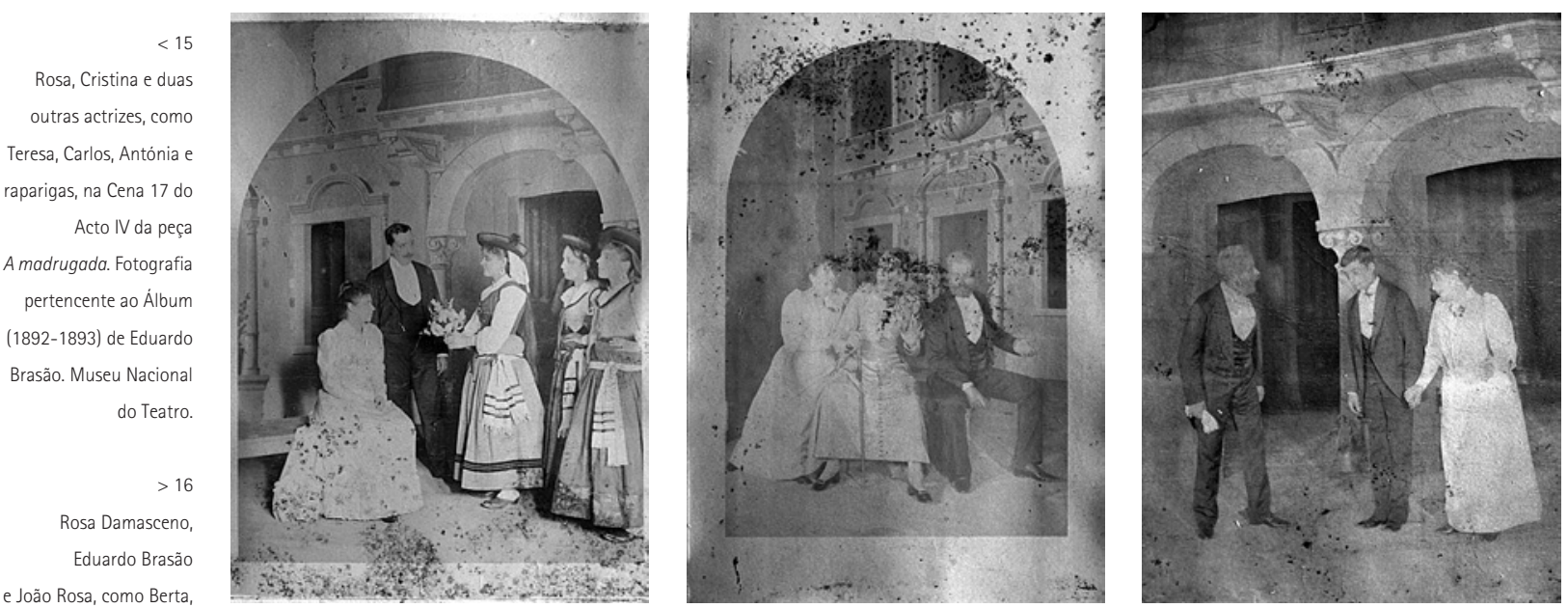

Monsenhor e Conde, na

Cena 27 do Acto IV da

peça A madrugada.

Fotografia pertencente ao

Álbum (1892-1893) de

Eduardo Brasão. Museu

Nacional do Teatro.

$>17$

João Rosa, Ferreira da Silva e Rosa Damasceno,

como Conde, Ângelo e

Berta, na Cena 28 do Acto IV da peça A madrugada. Fotografia pertencente ao Álbum (1892-1893) de Eduardo Brasão. Museu

Nacional do Teatro.

Montagem a partir das

três fotografias do Acto

IV, em que resulta perceptivel grande parte

do cenário. experimental e pioneiro de que este conjunto de fotografias se reveste, antecipando uma tendência que se vulgariza alguns anos mais tarde. Aceitando esta atribuição, estaremos a falar do primeiro caso documentado em Portugal desta prática, inclusive anterior aos primeiros exercícios do género em França. Chantal Meyer-Plantureux refere-se à fotografia realizada em 1898, por Boyer, de Sarah Bernahrdt numa cena de La ville, de Gabriele d'Annunzio com o cenário original, como "Um testemunho notável, pois ainda muito raro. Será necessário aguardar pelos anos 20 para que a fotografia de teatro assuma o seu crescimento real"2 (Meyer-Plantureux e Dort 1992: 16). Também em Portugal, só no início do século $X X$ se tornará corrente este modo de registar a cena,

${ }^{2}$ No original "Un abandonando lentamente o estúdio do fotógrafo para se témoignage remarquable car encore très rare. II

faudra attendre les années 20 pour que la photographie de scène prenne son véritable essor." construir cada vez mais em torno do palco e configurando novas gramáticas visuais.

Agradece-se ao Museu Nacional do Teatro e ao Teatro Nacional D. Maria II a cedência das imagens para esta publicação.
Referências bibliográficas

BALK, Claudia (2002), "'Theatricality" and photography - iconographic similarities in nineteenth-century role portraits: postures, costumes and spatial situations", in Christopher Balme, Robert Erenstein e Cesare Molinari (eds.), European Theatre Iconography Conference. Roma: Bulzoni Editore

CALDEIRA, Fernando (1894), A madrugada, comédia em quatro actos (original em verso). Lisboa: M. Gomes.

MEYER-PLANTUREUX, Chantal e DORT, Bernard (introd.) (1992), La photographie de théâtre ou la mémoire de l'éphémère. Paris: Éditions Paris Audiovisuel. SANTOS, Vitor Pavão dos (1979), A Companhia Rosas \& Brasão. Lisboa:

Museu do Teatro / Secretaria de Estado da Cultura / Direcção Geral do Património Cultural.

SENELICK, Laurence (2002), "Theatricality before the camera: the earliest photographs of actors", in Christopher Balme, Robert Erenstein e Cesare Molinari (eds.), European Theatre Iconography Conference. Roma: Bulzoni Editore.

\section{Referência electrónica}

OPSIS - Base Iconográfica de Teatro em Portugal [opsis.fl.ul.pt] 